\title{
ENSAIO
}

\section{EU-TU-NÓS: A DIMENSÃO ESPIRITUAL DA ALTERIDADE NOS CICLOS DE CONTATO}

JORGE PONCIANO RIBEIRO

\begin{abstract}
Resumo: Este é um estudo teórico sobre a relação entre quantidade e qualidade, como um caminho para a compreensão dos conceitos "diferença e alteridade". "Eu,Tu, Nós" são três palavras e cada uma tem o seu próprio significado, como se fossem três quantidades que especificam a natureza diferente de cada uma. De outro parte, "Eu-Tu-Nós" é uma única palavra, cujo significado não vem de cada palavra isoladamente, porém da qualidade que o conjunto, como um todo, possui. "Eu, Tu, Nós" tem a ver com quantidade e com diferença, enquanto "Eu-Tu-Nós" tem a ver com qualidade e com alteridade. A quantidade separa e identifica, a qualidade une e especifica, a alteridade distingue e sintetiza, a espiritualidade relê e transcende. Os ciclos são processos subjetivos da passagem da quantidade para a qualidade, da imanência para transcendência e eles representam as diferentes fases da qual a alteridade se origina. A alteridade é um processo que permite a duas pessoas, que contemplam um único objeto, vê-lo, de maneira diferente, porque a alteridade não está no objeto contemplado, mas na subjetividade de quem o contempla.
\end{abstract}

Palavras-chave: Alteridade, Contato, Espiritualidade, Transcendência.

A Gestalt-Terapia tem sido definida como Terapia do Contato.

Contato que chama, provoca, une, aproxima, transforma, socializa, mundaniza e poderíamos ir ao infinito, direcionando as mil formas de contato que presidem os nossos relacionamentos. Isto significa que o contato não pode ser fruto de coincidências, mas sim de possibilidades, pois traz, na sua essência, a possibilidade da criação. Contato não é fruto do acaso, mas de uma intencionalidade que dirige o encontro entre os diversos seres do e no universo, o contato é a alma que dita e dirige todos os passos evolutivos de nossa caminha.

Nada mais sério, mais provocante e mais responsabilizante que definir Gestalt-Terapia como terapia do contato, pois isto significa, em primeiro lugar, que nós, gestaltistas, ao nos definimos como terapeutas do contato, temos que estar atentos e plenamente conscientes de que estar em contato é nosso principal instrumento de crescimento e de trabalho e que, em segundo lugar, reconhecemos que todos os seres estão imersos num cósmico processo de trocas, de contato, que é a máxima energia que preside todo o processo evolutivo.

Estar em contato é muito mais que estar atento, que estar consciente de si e do outro. Estar em contato é se tornar cúmplice com e da totalidade do outro, é, de algum modo, estar sem opção, pois, enquanto o outro permanecer um outro ou outrem para mim, estarei apenas em contato comigo mesmo, e o outro, aquele que me faz face, continuará um desconhecido, tornando presente para mim a dificuldade de me tornar eu mesmo, pois não chego a mim apenas através de mim mesmo, mas através do outro. 
Fazer, de fato, contato com o outro é a mais radical das possibilidades que o outro me apresenta, pois, enquanto ele estiver diante de mim como o outro ou como outrem, dificilmente ele me olhará como sendo eu parte integrante dele mesmo.

Este é o grande impasse existencial que se apresenta a qualquer psicoterapeuta, pois, como poderá ele sair de si mesmo para uma imersão na existência do outro, se este outro não se encontra no lugar do encontro ou se o lugar do encontro estiver plenamente ocupado por mim mesmo.

Em termos de realizar um contato pleno, não existem muitas saídas, apenas uma: saltar na direção do outro, ainda correndo o risco de que ele não esteja lá, porque um autêntico salto na direção do outro é, no mínimo, um salto na direção de mim mesmo. E, enquanto isto não acontecer, qualquer salto na direção do outro será um salto no vazio.

Estou dizendo que só somos reais, na razão em que o outro é real para nós, pois somente quando caminhamos na direção do outro, é que, a meio caminho, nos encontramos conosco mesmos.

Se esbarro na minha ontológica pergunta: Quem sou ou como será penetrar no mistério do outro? Creio que aqui também só existe uma resposta: é não perguntar, mas deixar-se conduzir pela vivência da única experiência possível, penetrar vagarosamente no próprio mistério e deixar que nosso amor pelo outro nos revele quem somos nós e quem é ele.

O outro é parte do mistério que se esconde em mim e para mim à espera de ser revelado e eu sou a possibilidade de revelação do que nele se oculta.

Estamos saindo do mundo das aparências para o mundo do real, saindo do mundo do igual para o mundo do diferente. Só aparentemente, o mundo do outro é o mundo do diferente, porque, na verdade, somos tão iguais, tão semelhantes. O outro, pensamos, é o diferente de mim, ele é aquilo que eu não sou ou ele não é o que eu sou e, no entanto, nem sempre o mundo do igual torna duas pessoas iguais, porque tanto o igual quanto o diferente são diferentes um do outro para o outro.

Somos atraídos pela aparência do outro. É ela que nos conduz até o outro. Ela nos convida, nos instiga, nos seduz, nos silencia, nos faz medo. Eu paro, observo e, em frações de minutos, meu computador me dá pronto o retrato do outro. É a totalidade intuitiva dos primeiros minutos.

As aparências não enganam. Isto é silenciosamente universal. Parece que temos no olhar a mesma máquina fotográfica mental, cuja bateria se chama medo, prudência, risco, cultura, preconceito. E, às vezes, quando revelamos o filme das nossas impressões, temos a sensação de que as aparências nos enganaram e, aí, tentamos bater novas chapas, na ilusão de encontrar o que esperávamos. E aí intuímos que as aparências não enganam, apenas não revelam tudo.

Assim, curiosidade e subjetividade estão sempre a meio caminho entre a realidade em si e nossa visão objetiva. As coisas não têm sentido em si, o sentido é sempre um encontro, que nem sempre acontece, porque o sentido não nasce de uma relação causa-efeito, mas da procura despretenciosa do outro. 
Neste contexto, podemos entender que a questão da alteridade passa, assim, necessariamente, pelo modo como cada um de nós vê o mundo. Na verdade, a apreensão da realidade do outro é muito mais uma fabricação nossa do que a própria realidade dele apreendida pelos nossos sentidos, embora nada vá ao intelecto, sem antes passar pelos sentidos. Armazenamos em nós tudo aquilo de que necessitamos para o bom funcionamento do nosso sistema de auto-regulação organísmica.

Nosso corpo é feito de uma carne totalmente contaminada pela nossa história e como não é a carne que se faz palavra, mas é a palavra que se faz carne, nossa intuição perceptiva do outro está fatalmente contaminada pelo nosso corpo, pelo corpo do outro e pela nossa história.

As aparências, não obstante tudo isso, nos seduzem e nos falam, e, às vezes, de uma maneira, tão, aparentemente, clara, que, nos convencemos de que nossa percepção está correta e até tomamos atitudes preventivas, antes mesmo de qualquer contato com o outro. Isso é o predomínio da visão sobre a percepção, da quantidade sobre a qualidade, da matéria sobre a imaterialidade, da estrutura sobre sua organização.

Ver é, assim, apenas um olhar, um ato mecânico, um toque visual na realidade do outro. Perceber, entretanto, é ir além do fenômeno imediato, é parar atento na realidade do outro, é colher e examinar detalhes e descobrir vida lá onde apenas pareciam existir informações vazias.

Quantidade e qualidade são dois lados de uma mesma realidade. A quantidade, entretanto, tem intrínseco uma qualitas, espécie de alma, de energia que é diferente do quantum da qualidade que é também um suposto da quantidade e é o que nos leva a decidir. A qualidade dá vida, dá valor à quantidade. A matéria é um dado bruto, primitivo, original. É de ferro, é de pedra, é de madeira, dizemos. A qualitas, o imaterial no material, é uma espécie de sabor, de cheiro, de gosto, algo intrinsecamente inerente à matéria, e que é igualmente presente a todos os seres. O incenso, por exemplo, é material, mas emite um cheiro que vai além da matéria, uma qualitas que só esta matéria possui, como um proprium.

Esta qualitas individualizante e singular, presente na quantidade, é a essência da alteridade, ao passo que o quantum, universalizante e coletivo, presente na qualidade. É a essência do diferente.

Forma, estrutura e organização andam juntas. Uma cadeira, por exemplo, tem uma estrutura material que tem determinada forma, porque está organizada de um tal modo. É na matéria e através dela que estes construtos fazem sentido, mas, embora essas três dimensões aconteçam simultaneamente, em um dado objeto, elas se distinguem entre si e é esta distinção que cria a diferença entre um objeto e outro.

Distinguimos dois tipos de alteridade. Aquela presente a partir da diferença com o outro e que dificulta o contato com ele, e aquela que transcende a diferença e que forma um contato mais rico, porque a alteridade chama o olhar de ambos para a realidade deles com detalhes que nascem da busca espontânea do encontro. 
A primeira, portanto, é centrada na materialidade do objeto observado e a segunda, centrada na qualidade através da qual redimensionamos a quantidade a todo instante, extraindo dela, sob qualquer forma, toda a riqueza e potencialidade que ela possa oferecer àquele que a observa.

Alteridade, mais do que significar a individualidade singular de uma pessoa, ela é o que a distingue das demais, ela se exprime através dos modos de sentir, de pensar, de agir e de falar que alguém vive na sua relação com o outro, despertando, em ambos, atitudes que interferem na relação de um com o outro. Em si, o processo da percepção da alteridade não separa, apenas distingue, ao passo que o processo da percepção do diferente não apenas distingue, mas separa.

A alteridade está à base de todo processo criativo e de transformação. Ela é o gen de mudanças que permitiram e continuam permitindo que todo nosso processo evolutivo se realize. A união, a síntese das diferenças criam o novo. Não se trata de geração espontânea, casual, trata-se de um processo de inclusão, no qual as partes selecionam o que de igual as une. Nessa fase, ocorre a fecundação, para, num segundo momento, ocorrer o processo de multiplicação das células, de onde nasce o diferente que, anteriormente, uniu os corpos ou as partes.

Falta-nos a dimensão ontológica, metafísica do que significa diferença, porque estamos imersos na dimensão estética e rotineira dos iguais, embora, inconscientemente, quando contemplamos o belo, estamos sempre à procura do diferente, existente no objeto contemplado. O belo está fora do sujeito, ele precisa de distância para ser apreciado. O diferente não está nem lá, nem cá, está no “entre”. É no “entre” que a síntese ocorre, é no “entre” que tudo acontece, porque o "entre" é o lugar no qual a relação encontra seu verdadeiro significado.

Quando dizemos Eu, Tu, Nós, dizemos algo muito diferente de quando dizemos Eu-Tu-Nós.

Eu, Tu, Nós são partes em relação. São pronomes pessoais que registram uma geografia ou um espaço existencial, aonde não existe, propriamente, uma diferença, e sim, uma distinção que, do ponto de vista gramatical, registra três pronomes diferentes quanto à pessoa, mas iguais por serem pronomes.

Eu-Tu-Nós deixa de ser, gramaticalmente, pronomes pessoais, para significar e gerar uma relação, na qual, palavras, sem desaparecerem, revelam, entre si, um compromisso existencial, relacional, em que o "eu”, o "tu”, o "nós" se fundem e se confundem, indicando um espaço existencial de um processo de total cumplicidade: e aí, o pronome vira nome.

Estamos em um processo ascendente, à busca de uma significação que transcenda uma simples perspectiva ou um simples olhar para um processo se fazendo. Neste contexto, alteridade deixa de ser um simples construto para se transformar numa essência-processo que significa o resultado peculiar de uma fusão harmoniosa de diferenças. Estamos entrando no mundo da imaterialidade, da qualidade, das formas sem molduras inibidores.

Quando diferenças se encontram e se harmonizam, cessa a materialidade de ambos, e a alteridade, que é o conjunto que daí surge, se torna presente, 
permitindo-nos a re-leitura de uma outra realidade que se esconde numa realidade maior, a re-leitura do invisível presente na matéria e que surge da matéria como um perfume que uma flor exala, sem deixar de ser flor. Estamos entrando no mundo do espírito pensante, da imaterialidade, da espiritualidade.

Quando o Eu, o Tu e o Nós desaparecem no mundo do Eu-Tu-Nós, desaparece a dimensão espacial limitante e surge a dimensão primeira do tempo, a consciência, aonde o limite é o possível. Cessam os limites limitantes, surge a dimensão temporal que nos convida à expansão e a nos perdermos de nós mesmos em busca da máxima aventura de encontrar a si próprio, de se comprazer e de se encantar consigo mesmo.

Isto é encontrar-se com a espiritualidade em ação, aqui-agora, parte-todo se confundindo, gestalt plena se fazendo.

Materialidade, espiritualidade. Opostos? Não. Apenas realidades vistas a partir de diferentes ângulos.

Buber afirma que todo o profano espera para se tornar sagrado. O profano é o momento pré-reflexivo do sagrado. Ele é o básico, o inicial, o primitivo, uma figura à espera de um novo olhar, um olhar que, sem destruir seu original, seu primitivo, lance sobre ele uma re-leitura, de tal modo que, sem deixar a profanidade que contém em si, transcenda si mesmo.

Estamos falando de intersubjetividade entre o silêncio e a fala, entre a matéria e sua aparência, entre a coisa em si e o em si da coisa, estamos falando de uma relação fenomenológica eidética transcendental, de tal modo que este ser encontre, através de uma ré-leitura, uma de suas essências singulares e individualizantes. Este é o campo da alteridade.

Este é o mundo do encantamento, no qual o sagrado toma o lugar do profano, a matéria se transfigura em mil possibilidades, transcendendo para o mundo da espiritualidade.

A alteridade que antes se colocava entre o profano e o sagrado, é agora o elemento princípio de toda síntese, elemento que permite a todo ser, sem deixar de ser ele, incluir-se holisticamente na multidão de possibilidades que todo ser apresenta e, assim, transcender, fazendo a ponte entre o igual e o diferente, que constituem o substratum de toda a realidade.

A alteridade não é, necessariamente, o que separa dois seres ou coisas, nem é o que separa uma coisa da outra, tornando-a a outra, nem é o que duas pessoas, ou até uma, vêem como diferentes a partir de seu mundo subjetivo.

A alteridade é, simplesmente, o lugar onde mora a diferença, não a diferença que separa um objeto do outro, mas o que faz duas pessoas verem como diferente, em um único objeto e momento, uma mesma realidade.

A alteridade, neste contexto, distingue qualidades e não quantidades, ela não nasce do encontro de duas matérias brutas, mas do surgimento da percepção das possibilidades que um único objeto, contemplado por uma ou mais pessoas, contém em si.

A essência da alteridade emana da unidade e unicidade do objeto e repousa na multiplicidade de suas possibilidades como existente, pois, não obstante, ser 
única, singular e individual, a realidade se oferece para ser mil possibilidades para o olhar que a contempla.

O mesmo processo constitui também a essência da espiritualidade. O objeto contemplado inunda a mente contemplativa de suas mil possibilidades, de tal modo que, ao descobrir suas mil possibilidades ou diferenças, o objeto se transcende, levando a mente contemplativa, ao transcender suas possibilidades, a superar todo vínculo de materialidade, de tal modo que sua essência seja simplesmente ser um ser de infinitas possibilidades.

Mas é nossa percepção, transformada em contemplação, que nos transporta da imanência para a transcendência que é a aceitação amorosa da interdependência de todas as coisas, quando tudo é resignificado e aonde um contato pleno se transforma em uma gestalt plena.

A alteridade tem também suas raízes na interdependência de todas as coisas e, por sua vez, a interdependência entre todas as coisas é a essência criativa da evolução que gera uma infinitude de estruturas e formas que se organizam a partir da imanência da totalidade que constitui todos os seres.

Todas as coisas têm imanente em si a totalidade, pois é ela que define a essência dos seres, sendo o processo evolutivo um processo de transferência de totalidades, de gestalten plenas. Só quando um ser atinge sua totalidade, uma totalidade, aqui-agora, é que ele desponta para um novo ciclo de horizontes evolutivos. Só quando um ser é pleno de qualidade, ele se abre para novas quantidades que é o carro chefe do processo evolutivo.

Acredito que a alteridade é um dado que caminha entre quantidade e qualidade e talvez eu possa dizer que a quantidade está para imanência, assim como a qualidade está para a transcendência e que o que rege todas estas propriedades é a interdependência.

Observo que a interdependência das coisas não é algo fixo, estático, que trava o processo de mudança. Ao contrário, interdependência gera energia e movimento de e para a mudança, pois ela é a força, o elo que liga o igual de duas realidades, permitindo que o diferente emerja.

O universo funciona em ciclos, tudo nele é cíclico: as estações, os ciclos lunares e solares, as marés, a menstruação e mais uma infinidade de fenômenos. Os ciclos são formas complexas de contato, através dos quais tudo se organiza no universo através de períodos ou revoluções, sempre iguais no que diz respeito ao tempo, e que tendem a repetir-se na mesma ordem.

Observo que a palavra ciclo, vem etimologicamente do grego kyklos que significa círculo. Daí apresentamos nossos ciclos em forma de círculos.

O ciclo é um sistema operacional através do qual uma dada realidade retorna aparentemente com o mesmo programa, mas carregada agora das energias ou qualidades de todo um percurso anteriormente feito. No nosso contexto, é também duração, mas não uma duração matematizada, quantificada, mas, ao contrário, ele registra o tempo vivido em que as qualidades da experiência sinalizam processos de mudança em curso. É movimento em ação, contínuo, com começo, meio e fim. 
É uma síntese processual, porque ele espera seu próprio retorno, embora nunca passe pelos mesmos pontos anteriores, de maneira idêntica à primeira vez.

O ciclo nunca está pronto, ele parece pronto. Ele é a medida do processo evolutivo. Caminha para frente e para cima e registra em si toda a transcendentalidade das coisas que têm ínsita a vocação para a plena realização. É constituído de momentos, de fases, de passos que caminham sempre à procura de sua própria inteligibilidade e completude. É como uma gestalt plena, cuja totalidade é fruto de um complexo processo de contatos à procura de completar-se sempre, para, em seguida, dar início a um novo ciclo.

Todo ato, resultante de uma potência no pico de suas possibilidades, está pronto para iniciar um novo ciclo, uma nova criação. Um ciclo só gera o início de um outro, quando este atingiu sua máxima possibilidade de rendimento. A paciência do universo é a responsável pelas suas mudanças numa ordem de crescente complexidade, de tal modo que, somente quando uma gestalt se completa, se torna plena, ela dispara, novamente, todas suas possibilidades de dar início a novos ciclos.

Uma gestalt só é plena, quando ela atualiza todas suas possibilidades de qualidades, quando ela se transforma numa totalidade, e aí ela se predispõe para um novo ciclo, para uma nova caminhada, e, se abre em infinitas partes, nas quais a quantidade recomeça seu longo caminho de se transcender em qualidades.

Esta é a metafísica do ciclo, que toda quantidade se transfenomenalize em qualidade e que toda qualidade se transforme em uma gestalt plena.

Evolução é o caminho que dá lugar ao surgimento do diferente e para a perspectiva de que novos ciclos se iniciem transitando da pura materialidade para a imaterialidade de uma qualidade superior

Evolução é caminhar para o diferente através de ciclos diferentes, nos quais todo o universo persegue objetivos, resultados cada vez melhores, cada vez mais visíveis e reais, porque, no processo evolutivo, as escolhas cósmicas obedecem a uma sagrada teleologia em que a realidade acontece a partir das necessidades básicas de uma construção de um mundo cada vez melhor.

Evoluímos, também, transcendendo a alteridade que mora em todas as coisas através da intuição das essências do mundo contemplado, podendo, assim, ascender, à uma mais consistente espiritualidade de onde tudo parte, para onde tudo converge e onde todo significado se completa.

Evoluir é transcender do igual para o diferente e, não fora a interdependência de todas as coisas, a evolução não seria possível, porque o caos seria a fixação de todo movimento de mudança. A alteridade tem, portanto, na interdependência de e entre todas as coisas seu processo natural de sustentação.

O diferente gera a alteridade e a alteridade é o princípio ativo que move a evolução. Evoluir é fazer eclodir em possibilidades o diferente que mora no ser à procura de se tornar mais um outro. Evoluir é um mágico processo de criação, no qual um ser se predispõe para se tornar infinitos outros, em infinitas partes diferentes do ser que as originou. Talvez eu possa dizer que a ordem divina "crescei 
e multiplicai-vos" possa ser re-dita como "evolui, descobri e gerai todas as vossas possibilidades". Evoluir, portanto, significa a tentativa de se esgotarem, em ação, todas as possibilidades de transformação que um ser encerra em si.

Imaginai todos os seres do universo, seguindo seu instinto evolutivo, obedecendo, ao primeiro chamado, à ordem divina: evolui, buscai e realizai todas as vossas possibilidades. O resultado não poderia ser outro a não ser este show cósmico de transformações, de beleza e simplicidade que o universo nos apresenta a todo instante.

Se passamos do panteísmo para o panenteísmo, só nos resta dizer que a evolução é a demonstração mais clara da presença criativa de Deus. Este universo é o resultado final da evolução que ocorre em ciclos, evolução que nos permite ver o diferente se fazendo em ciclos de transformação, sem que jamais parte de sua estrutura inicial e anterior se perca na sua forma posterior, em caráter absoluto. Alteridade absoluta também não existe e é por isso que podemos, não apenas metaforicamente, dizer que somos irmãos do sol, da lua, das estrelas e do mais ínfimo dos seres.

Estamos no mundo do encantamento, do deslumbramento, da imaterialidade, da espiritualidade, o mundo no qual as diferenças não "registram" alteridades, mas a unidade original de todos os seres. A alma de tudo isto é o contato que, em ciclos holográficos, vai permitindo que todos os seres, de algum modo, se transformem sem jamais se repetirem e, ao mesmo tempo, contendo, em cada uma de suas novas partes, a totalidade que a precedeu.

Não existem, portanto, gestalten plenas, cheias, porque, em um todo, apesar de ser um todo e como tal se apresentar, suas partes se encontram, internamente, em graus diferentes de evolução e é esta diferença que cria a alteridade entre elas, alteridade que está mais no reino da qualidade do que da quantidade, o que permite ao organismo funcionar como uma unidade equilibrada e sempre à procura de sua auto-regulação organísmica.

Não fora a harmonia causada pela alteridade das partes, o organismo funcionaria caoticamente, porque o que distingue o coração do pulmão não é que eles são diferentes, mas que o coração é um outro com relação ao pulmão e ambos habitam um único e autêntico ser, o corpo, mágica síntese de alteridades de uma totalidade em ação.

É, portanto, a alteridade a alma da harmonia corpo-mente-ambiente e não a convivência das diferenças. A alteridade é o aspecto imaterial que reside na diferença, que é o que separa duas quantidades. A diferença, neste caso, separa, a alteridade distingue. A alteridade não cria diferenças, ela é a superação, a transcendência da diferença.

A espiritualidade é o desabrochar da alteridade, no sentido de que é através da alteridade que o ser se encontra com todas as suas possibilidades. Na razão em que o outro, que mora no outro, desabrocha, mais ele revela sua beleza, como uma flor que, ao desabrochar, revela todas as suas escondidas possibilidades de ser admirada. 
Eu-Tu-Nós. O "Nós” é a alteridade em transcendência a caminho de uma espiritualidade de comunhão comunitária em que o " eu e o tu" vivem uma absoluta provisoriedade à busca de se tornar um "nós".

Eu-Tu-Nós. O "Nós" é a sublimação, ou, melhor dizendo, é a alteridade em transcendência, porque ele é a síntese das diferenças entre o "eu" e o tu". O "Nós" não é uma soma de "eus" e de "tus", ele é a expressão, a exteriorização de um contato que mexe na própria natureza da quantidade, dando nova forma ao encontro das diferenças pela assimilação do que de igual o ser encerra em si.

O “Nós” não é necessariamente o encontro do "eu e do tu”, simplesmente, mas do "eu" com um "tu" que é o outro, seja este outro pessoa ou qualquer coisa no universo, e que entrou no campo perceptivo de quem o observa, permitindo uma vivência transformadora da própria natureza constitutiva da relação intrasubjetiva pessoa-mundo.

O “Nós” é a transcendência da relação "Eu-Tu”. O "Nós” é a espiritualidade consubstanciada na alteridade que emana do Eu e do Tu. Quando o Cristo disse: "Eu e o Pai somos Um”, este "Um” é o "Nós" que nasceu da diferença entre o Pai e o Filho, diferença que não separa um do outro, mas os consubstancia pela alteridade de uma mesma natureza, porque, na realidade, são duas pessoas em uma única natureza. Temos aqui um exemplo de como o "Nós" é metafisicamente um. O nós é a máxima expressão da transcendência de diferenças concretizadas na natureza de duas realidades em interação.

Estamos falando de um tipo de contato que transcende qualquer tipo de fronteira, que invade o campo como uma totalidade, cujo espaço vital não pode mais ser pensado como zonas periféricas e centrais, porque, no "Nós", desaparecem o Eu e o Tu, ou o Eu e o Tu formam um fundo cuja figura transcende o Eu e o Tu pela superação de toda e qualquer fronteira. O "Nós" é o horizonte no qual desaparecem o Eu e o Tu e no qual ou do qual nasce a possibilidade de integração total das partes. O "Nós” não é a soma do Eu e do Tu, ele é a superação dos limites que aprisionam tanto o Eu como o Tu às quantidades condicionadoras do ser.

Quando penso eu e tu, quando digo nós, estou somando minha realidade à do outro. Nós é plural de eu. O outro é sempre o outro para mim, até que, de tanto percebê-lo, não olho mais as quantidades que o definem, mas lanço meu olhar para além de mim mesmo e dele, procurando o invisível, o mistério que mora nele e, como numa espiral cíclica, vou, num eterno crescendo, me deparando com a alteridade que nos unifica pela superação ou transcendência de nossa intersubjetividade, e, neste instante, nos tornamos Nós.

Contato é, portanto, o instrumento de transformação de todos os seres. Sem contato a realidade pára, se estagna e morre. Estamos todos em contato, que é a alma que preside a evolução no e do universo. Estamos em contato, todos, queiramos ou não. Não é nossa vontade que determina a entrada ou saída do contato, porque é de nossa natureza sermos contato e ele significa e gera vida, movimento, inclusão, mudança. 
Apesar de sermos, intrinsecamente, contato, selecionamos, é verdade, os contatos que fazemos. A perda, entretanto, da consciência de que somos, necessariamente, contato, facilita a interrupção do fluxo vital que gera saúde, evolução e uma maior potencialização do nosso ser. Neste sentido, o "Nós" é a síntese dinâmica de todas as diferenças, é a gestalt plena, na qual todas as partes se confundem e se fundem num grande todo.

No "Nós" a alteridade se consuma pela manutenção da especificidade ontológica do Eu e do Tu.

Temos dito somos cíclicos, vivemos em ciclos físicos, existenciais e espirituais. Às vezes, percebemos a presença ou ação dinâmica de um ciclo mais do que de outro, o que depende da percepção de que parte do caminho estamos vivendo, mas, na realidade, como no processo evolutivo, não se pode distinguir um do outro, embora possamos, sim, sentir, pela experiência do tempo e do espaço, agora vividos, que todo o nosso ser está em processo de mudança, mudanças, que, muitas vezes, só são percebidas a posteriori e, aparentemente, não dependeram do momento ou da experiência que as provocaram.

É através de mudanças cíclicas que nos experimentamos como seres de movimento e de mudança, eé através destas mudanças que nosso processo de alteridade ocorre, e cujo processo nos revela, paulatinamente, que eu sou eu, mas, ao mesmo tempo, que um outro outro nasceu ou está sempre nascendo dentro de mim.

Quanto mais amorosamente eu olho para este outro outro que está nascendo, tanto mais uma nova "qualitas" me transporta para o mundo do encantamento sobre mim mesmo. Quanto mais me abro para acolher minhas mudanças tanto mais me conecto com o cosmos que é a grande mãe geradora de toda mudança, de toda diferença e de toda alteridade.

Estar conectado com o cosmos, sobretudo, com a mãe terra, é estar aberto para deixar nascer em si toda uma possibilidade de evolução e de crescimento. Acolher amorosamente o outro que nasce em mim é lançar raízes para uma transcendência que desembocará, infalivelmente, em níveis mais sutis de espiritualidade, cada vez mais profunda.

A espiritualidade, entretanto, precisa ser procurada, desenvolvida. Não evoluímos sem um real engajamento de procura de nós mesmos e do mundo. $\mathrm{O}$ crescimento espiritual é uma luta, não chega de graça e sem um grande esforço, embora não seja como um horizonte que quanto mais se caminha na direção dele, mais distante fica.

A espiritualidade é uma conquista, fruto de uma insistente ousadia de uma caminhada sem fim à procura de nós mesmos e do sentido último das coisas. Ela está aqui e está lá. Não tem um lugar certo, mas é certo que seu lugar é o coração e a mente abertas para uma resignificação constante da realidade que nos cerca.

A alteridade do olhar virou o olhar da alteridade, o outro que eu via no outro, não é mais o outro, porque, quando as diferenças não importam mais, a alteridade, como dois perfumes diferentes que emanam de uma única essência, se unifica sob o olhar de quem observa, e ai a ciência vira arte e a saúde vira um dom, uma graça. 
Temos que nos lembrar que o grande instrumento para nossa evolução humana e espiritual é o amor, que chamo de energia primária universal. Ele é a argamassa que preside ao real processo evolutivo humano e cósmico. $\mathrm{O}$ amor é a única gestalt plena, cheia, porque o amor só ocorre, quando a parte se dilui no todo, quando quantidade e qualidade se confundem, quando a essência de algo se confunde com sua existência, vivenciada, aqui-agora, através de uma consciência emocionada e transformadora.

O amor, síntese das diferenças e transcendência da alteridade, é inteiro, individual, comunitário, cósmico e quanto mais essência e existência se confundem ao olhar atento de quem observa a realidade, mais a quantidade vai se tornando qualidade, mais beleza e encantamento ganham forma, mais o profano dá lugar ao sagrado e, paradoxalmente, a palavra vira carne, e aí, as diferenças não importam mais, a alteridade entre o "Eu" e o "Tu" desabrochou no "Nós", o divino se humanizou, o humano se divinizou através de um contato, que se transformou em uma gestalt plena, cheia, divinamente humana, chamada AMOR.

\section{Referências Bibliográficas:}

Ribeiro, J.P. (2005). Do self e da ipseidade: uma proposta conceitual em gestaltterapia. São Paulo: Summus editorial.

Ribeiro, J.P. (2006). Ruídos: contato, luz, liberdade: um jeito gestáltico de falar do espaço e do tempo vividos. São Paulo: Summus editorial.

Ribeiro, J.P. (2006). Vade-mécum de gestalt-terapia: conceitos básicos. São Paulo: Summus editorial. 
Abstract: This is a theoretical study, concerning to the relation between quantity and quality, as a way for understanding difference and alterity. "I, You, We" are three words, each one with its own meaning, as they were three quantities that determinate the different nature of each one. On the other side, "I- You- We" is only one word, whose meaning does not come from each word seen separately, but from the quality that the whole contains. "I, You, We" refer to quantity and difference, while "I- You- We" refers lo quality and alterity. The quality separates and identifies, quality unities and specifies, alterity distinguishes and synthesises, spirituality rereads and transcends. Spirituality is a process that emanates from the alterity through which a single object can be seen or contemplated, in a different way, at the same time, by two other peoples. Alterity refers to immateriality, to qualities that makes only one object to be the "alter" for two people that contemplate it, at same time. The cycles are the subjective processes of the passage from quantity to quality, from immanence to transcendence and they represent the different phases from which alterity originates. The alterity is a process that permits to two peoples who contemplate one only object to see it in a different view, because the alterty is not in the contemplated object, but in the subjectivity of whom contemplates it.

Key-words: Alterity, Contact, Spirituality, Transcendence.

Resumen: Este és un estudo teorico sobre la relación entre cuantidad y cualidad, como um camino pera la comprensión de los conceptos “diferencia” y "alteridad”."Io, Tu, Nosotros" son tres palabras y cada una tiene su próprio significado, como se fueran tres cuantidades que especifican la diferente naturaleza de cada una. De otra parte, "Io-Tu-Nosotros" és una unica palabra, cuyo significado no viene de cada palabra isoladamente, pero de la cualidad que el conjunto, como um todo, significa."IoTu- Nosotros" tiene que veer com cuantidad y com diferencia, mientras "Io-Tu-Nosotros" tien que veer com cualidad y con alteridad. La cuantidad separa e identifica, la cualidad une y especifica, la alteridad distingue y sintetiza, la espiritualidad hace una nuova lectura y transcende. Espitualidad es um proceso que emana de la alteridad através de la qual um unico objecto puede ser contemplado, de modo distincto, por dos personas al mismo tiempo. Alteridad tiene que veer com imaterialidad, esto es, com las cualidades que hacen un único objecto ser um " alter" para dos personas que lo contemplam. Los ciclos son procesos subjectivos del pasage de la cuantidad para la cualidad, de la imanencia para la transcendencia e ellos representam las diferentes fases de las cuales la alteridad nace. La alteridad es um proceso que permite a dos observadores que contemplan un unico objeto, veerlo como diferente, porque la alteridad no está em el objecto, pero en la subjetividad de quien lo contempla.

Palabras-clave: Alteridad, Contacto, Espiritualidad, Transcendencia.

Jorge Ponciano Ribeiro é graduado em Filosofia e Teologia, Mestre e Doutor em Psicologia, Professor Titular Emérito da Universidade de Brasília. 